\title{
Deposition of thin films using argon/acetylene atmospheric pressure plasma jet
}

\author{
Alonso H. Ricci Castro *, Felipe V.P. Kodaira, Vadym Prysiazhnyi, Rogerio P. Mota, Konstantin G. Kostov
}

Faculty of Engineering, Campus Guaratinguetá (FEG), Sao Paulo State University (UNESP), Guaratingueta, Sao Paulo, Brazil

\section{A R T I C L E I N F O}

\section{Article history:}

Received 4 March 2016

Revised 11 July 2016

Accepted in revised form 12 July 2016

Available online 14 July 2016

\section{Keywords:}

Plasma polymers

Plasma jet

Acetylene

Atmospheric pressure plasma

\begin{abstract}
A B S T R A C T
Atmospheric pressure plasma jet was used to deposit polymer films from argon/air/acetylene mixture. Depending on the gas composition, three modes of operation were observed and characterized. The film deposited by a stationary jet had a circular shape with area (where thickness was almost constant) about the nozzle inner diameter. The deposition rate of stationary jet decreased with the time: a film of $2 \mu \mathrm{m}$ was obtained after the first two minutes, while in the next two minutes only $1.3 \mu \mathrm{m}$ film was deposited. The plasma polymers were characterized by infrared spectroscopy, where variety of $\mathrm{C}-\mathrm{H}$ and few $\mathrm{C}-\mathrm{O}$ bonds were detected. By using a linear displacement system, we obtained homogeneous deposition over a larger area with deposition rate of about $330 \mathrm{~nm} /$ min, showing the potential of such plasma jet system for large-scale depositions.
\end{abstract}

(c) 2016 Elsevier B.V. All rights reserved.

\section{Introduction}

In the last 20 years, deposition of thin films using cold atmospheric pressure plasma was investigated by several research groups with a principal goal of obtaining continuous plasma deposition process [1]. Different atmospheric pressure plasmas were tested for this purpose, including dielectric barrier discharges (DBDs) and plasma jets with different geometries and power [2-4]. Plasma polymers demonstrated favorable properties for many industrial applications and high potential in medicine. For example, they exhibit high thermal stability (under $400^{\circ}$ C), chemical inertness and high degree of crosslinking compared to conventional polymers [5]. Different configurations of DBDs were intensively studied for preparation of surface coatings [6] and functional surface nanostructures [7]. Especially the capacity to grow functional coatings on any type of substrate makes atmospheric plasma processing an attractive technique for biomedical applications [8]. More recently, the atmospheric pressure plasma jets (APPJs) have been used to deposit bio-compatible films and nanocomposite coatings $[9,10]$. Different APPJs geometries and precursors have been studied [11-13].

The characteristics of plasma-deposited materials strongly depend on the choice of the precursor [12]. Majority of published works deal with deposition from methyldisiloxane precursors [13], for example, plasma polymerization of hexamethyldisiloxane in $\mathrm{He} / \mathrm{O}_{2}$ micro-jet achieved a deposition rate of $50 \mathrm{~nm} / \mathrm{min}$ varying the flows of precursor

\footnotetext{
* Corresponding author at: Faculty of Engineering, Campus Guaratinguetá (FEG), São Paulo State University (UNESP), Av. Dr. Ariberto Pereira da Cunha 333, Portal das Colinas, Guaratingueta, Sao Paulo, Brazil.

E-mail address: Alonso_elfisico@yahoo.com (A.H. Ricci Castro).
}

and oxygen admixture [14]. A comparison of HMDSO/Ar deposition using atmospheric pressure plasma jet and low pressure reactor was done by Kedronova et al. [15]. Authors showed that APPJ system can produce films with similar chemical structure as the ones obtained in low pressure systems, but with different surface morphology. The roughness of those films depends on applied power and can be varied in a wide range (from $2 \mathrm{~nm}$ to $120 \mathrm{~nm}$ ). Juang et al. [16] treated polyvinylidene fluoride membrane using APPJ in mixture of argon and methane. The analysis after the treatment shows an increase of wettability and the presence of $\mathrm{C}=\mathrm{O}$ bonds on the surface.

The properties of films deposited from acetylene plasma have been studied for long time, starting from low-pressure plasma reactors to atmospheric pressure ones [17-19]. It has been shown that plasma polymerized acetylene coatings have good adhesion. Also they exhibit inert behavior to acidic and basic solutions and can be used as barrier coatings or interface layers for immobilization of proteins [20,21]. Wemlinger et al. [22] polymerized acetylene in atmospheric pressure plasma chamber with deposition rate of $23 \mathrm{~nm} / \mathrm{s}$.

Capote et al. [23] reported that the variation of argon concentration $\mathrm{Ar} /\left(\mathrm{Ar}+\mathrm{C}_{2} \mathrm{H}_{2}\right)$ in a low pressure chamber changed the physical properties of films (deposition rate, roughness, adhesion, compressive stress and wear), showing that it was possible to grow acetylene films with desired characteristics for mechanical and tribological applications.

Manakhov et al. [24] reported films with good water stability and high concentration of carboxylic group using co-polymerization of acetylene and maleic anhydride in DBD system. These two characteristics made the films appropriate for biomedical applications. Leduc et al. [25] reported that plasma polymers can influence cell migration thus increasing the density of cells on the region where the acetylene film was deposited. 
Here, we report the result obtained from atmospheric pressure plasma depositions using Ar/air/acetylene mixtures. The proposed plasma jet system can be easily scaled and is attractive for surface coating applications. The APPJ was characterized by means of electrical measurements (current waveforms, dissipated power) and optical emission spectroscopy. The deposited films were analyzed using profilometry (film thickness analysis), scanning electron microscopy (film morphology) and Fourier transform infrared spectroscopy FTIR (chemical composition of plasma deposited films).

\section{Experimental setup}

Plasma depositions were performed on a homemade atmospheric pressure plasma jet system (Fig. 1a). It consists of a high voltage (HV) electrode (tungsten rod of $2 \mathrm{~mm}$ diameter) inserted inside a dielectric enclosure composed of three parts. The first one is a teflon piece for fixing the HV electrode and admitting the primary working gas (argon). The middle part is a pyrex glass tube (length $7 \mathrm{~cm}$ and $8 \mathrm{~mm}$ internal diameter). The third part is a teflon nozzle that has an inlet for admitting secondary gas (mixture of acetylene and air) and also a grounded electrode in a form of aluminum adhesive tape was wrapped on the lower part of the piece. It was decided to introduce secondary gas close to the jet nozzle to prevent the polymerization on the inner metal electrode. A second grounded electrode (aluminum disc of $35 \mathrm{~mm}$ in diameter) was located under a $4 \mathrm{~mm}$ glass table. The substrates (standard $1 \mathrm{~mm}$ glass slides) were placed on the glass table. When plasma depositions were done with moving substrate, the glass table was connected to home-made movement system (consisted of microcontroller system,

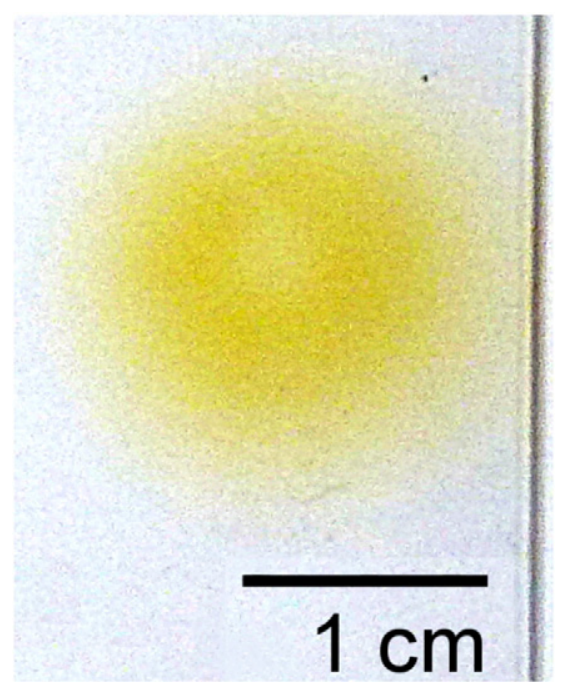

Fig. 2. Film deposition on glass substrate, nozzle-to-substrate distance: $4 \mathrm{~mm}$.

step motor and metal guide). A photo of the plasma jet is presented in Fig. 2b.

The plasma was ignited using a low frequency AC generator (Miniplus 4, Dresden Germany). It is composed of laboratory power supply (Voltcraft PS 3620), function generator (Rigol DG 1012) and

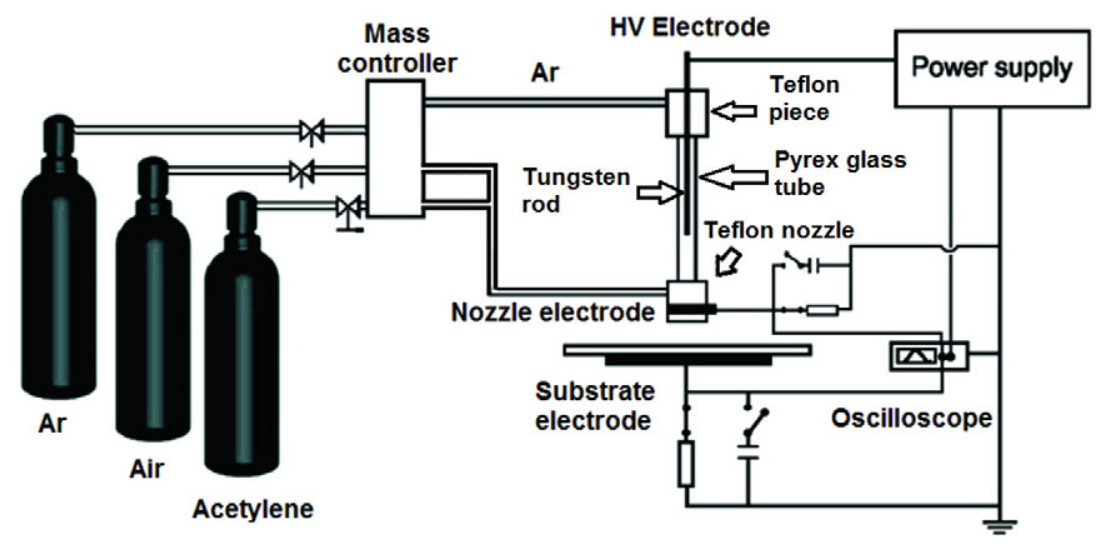

a

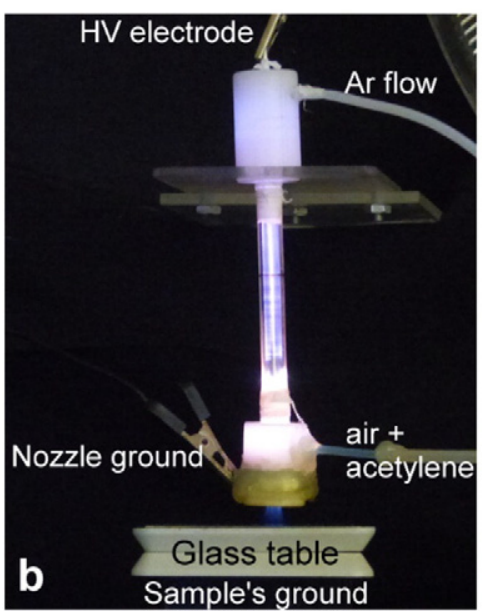

Fig. 1. a) schematic of atmospheric pressure plasma jet; b) photo of the plasma jet operated at conditions required to obtain film. 
Table 1

Power of APPJ with different gas mixtures.

\begin{tabular}{llll}
\hline Power $(\mathrm{W})$ & Nozzle & Substrate & Total \\
\hline $\mathrm{Ar}$ & $2.9 \pm 0.2$ & $8.0 \pm 0.2$ & $10.9 \pm 0.4$ \\
$\mathrm{Ar} /$ acetylene & $1.9 \pm 0.1$ & $2.0 \pm 0.1$ & $3.9 \pm 0.2$ \\
$\mathrm{Ar} /$ air/acetylene & $1.9 \pm 0.1$ & $0.8 \pm 0.1$ & $2.7 \pm 0.2$ \\
\hline
\end{tabular}

bank of transformers. The Miniplus 4 works as a resonance based circuit and generates a sine-like signal on output. Most experiments were carried out at $19.0 \mathrm{kHz}$ frequency and $17 \mathrm{kVp}$-p applied voltage. Due to a specific coupling between the power supply and plasma jet, one period $(\sim 52.6 \mu \mathrm{s})$ consists of two sine-like waves $(\sim 26.3 \mu \mathrm{s}$ each $)$ with higher and lower amplitude. Plasma is mostly generated during the higher amplitude semi-cycle, allowing us to avoid overheating issues.

The primary gas argon (99.99\%) was injected with flow rate of $0.45 \mathrm{~L} / \mathrm{min}$ into the enclosure while the secondary gas was introduced close to the jet nozzle. It was a mixture of acetylene $(0.045 \mathrm{~L} / \mathrm{min}$, 99.98\% purity supplied by AirLiquide, Brazil) and air (0.045 L/min, taken from compressor). The gas flow rates were controlled by a Horiba N100 mass flow controller.

The electrical characterization of the discharge was performed on a digital oscilloscope (Tektronix TDS 3032). The current of discharge was recorded using a Tektronix P2220 probe, measuring the voltage across a $100 \Omega$ resistor connected in series with the grounded electrodes. The transferred charge was measured using a serial capacitor of $10 \mathrm{nF}$ on the same way as the current measurements. The plasma was characterized by Optical emission spectroscopy (Andor Shamrock 303I equipped with CCD sensor and $600 \mathrm{~L} / \mathrm{mm}$ grating) and optical spectra were fit using SpecAir software. The film thickness was measured by a confocal Leica DCM 3D microscope using $100 \times$ magnification lens (analyzed area was $130 \mu \mathrm{m} \times 100 \mu \mathrm{m}$ ). The deposited film thickness was evaluated by measuring the depth of a stripe cut over the deposited film using medical scalpel on at least five samples for each deposition condition. It was confirmed that applying a moderate force on scalpel does not lead to scratches on the glass substrate (within measurement precision). The chemical composition of the deposited films was studied using ATR-FTIR spectroscopy on a PerkinElmer Spectrum 100 spectrometer with a single reflection unit (diamond). The spectra were recorded from $650 \mathrm{~cm}^{-1}$ to $4000 \mathrm{~cm}^{-1}$ with spectral resolution of $2 \mathrm{~cm}^{-1}$ and averaging over 32 scans.

\section{Results and discussions}

The electrical characterization of APPJ was done for three operation modes: when the jet operated with argon flow only, $\mathrm{Ar} /$ acetylene mixture or Ar/air/acetylene mixture. The method of Lissajous figures (also as the referred in literature as Q-V plot) was used to calculate the power transferred from the power supply to the discharge. In this method first is calculated the area of closed loop obtained for one cycle in coordinates "charge on external serial capacitor)" versus "applied voltage", and then is multiplied by the signal frequency. As the system had two grounded electrodes, the power was calculated for both of them and is presented in Table 1 for the three operation modes. It was observed that APPJ system can operate without the nozzle electrode, but the deposited films mostly consist of dust and deposit had white color (not shown here). On the other hand adding a nozzle electrode led to formation of a circular film of yellow color (Fig. 2). Electron microscopy measurements confirmed that the deposited film is flat on a micrometer scale. When the nozzle electrode is grounded, an optimum nozzle-to-sample distance to obtain dust-free films is $4 \mathrm{~mm}$ (all deposited films were prepared for this nozzle-sample distance). For shorter distances due to gas flow turbulence sparks between HV electrode and nozzle electrode occur, and for larger distances polymerization take place in gas phase and deposited films contain lots of low-adherent powder particles.

When the APPJ was operated with Ar only, the total power (the power at the discharge plus the power transferred to the substrate) was about $11 \mathrm{~W}$, and it dropped to $2.7 \mathrm{~W}$ when the jet was operated with Ar/air/acetylene mixture. It is important to note that the power measured on the nozzle electrode (which corresponds to the plasma inside the dielectric enclosure) does not change substantially, while a significant decrease was detected for the power delivered to the substrate. It decreased from $8 \mathrm{~W}$ to $2 \mathrm{~W}$ (in the case of Ar/acetylene) and $0.8 \mathrm{~W}$ (in the case of $\mathrm{Ar}$ /air/acetylene).

Since the secondary gas was injected at the jet nozzle the electrical properties of plasma ignited inside the dielectric enclosure (measured at the nozzle electrode) did not exhibit significant differences with variation of gas composition.

Fig. 3 shows a typical current waveform (Fig. 3a) and corresponding averaged Lissajous figure recorded from the nozzle electrode (Fig. 3b) when APPJ was operated with Ar/air/acethylene mixture. The HV signal has two sine-like cycles of different amplitude. The shape of Q-V plot is affected by the HV signal, it has two enclosed loops one for each sinelike cycles [26]. The only difference observed for the other modes of operation was that the amplitude of the current peaks was higher for operation with pure argon.

However, the Lissajous figures obtained from the substrate electrode show visible shape differences for operation in argon only or in $\mathrm{Ar} / \mathrm{air} /$ acethylene mixture (Fig. 4). The acetylene and air addition led to decreasing of the power transferred to substrate electrode. For DBD the Lissajous figure can be used to estimate the capacitance of full system and the capacitance of the dielectric layer $[27,28]$. However for APPJ (especially in our case with different amplitude semi-cycles) the Lissajous figures have quite complex shapes. Yet, it can be seen in Fig. 4 that when
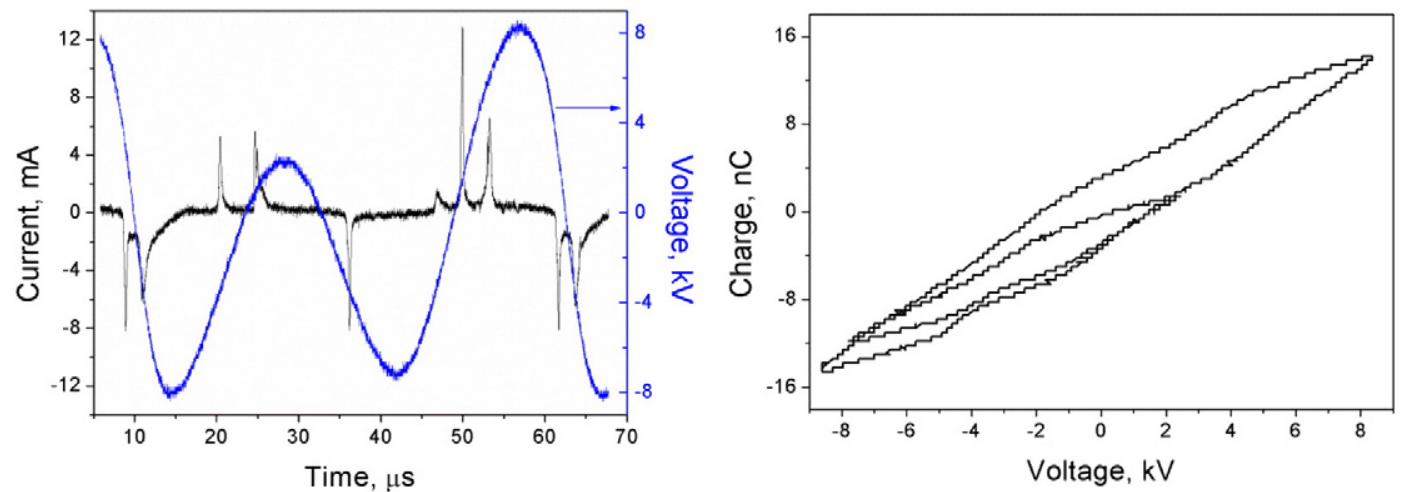

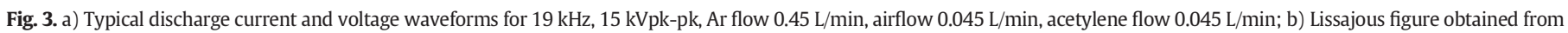
the nozzle electrode. 


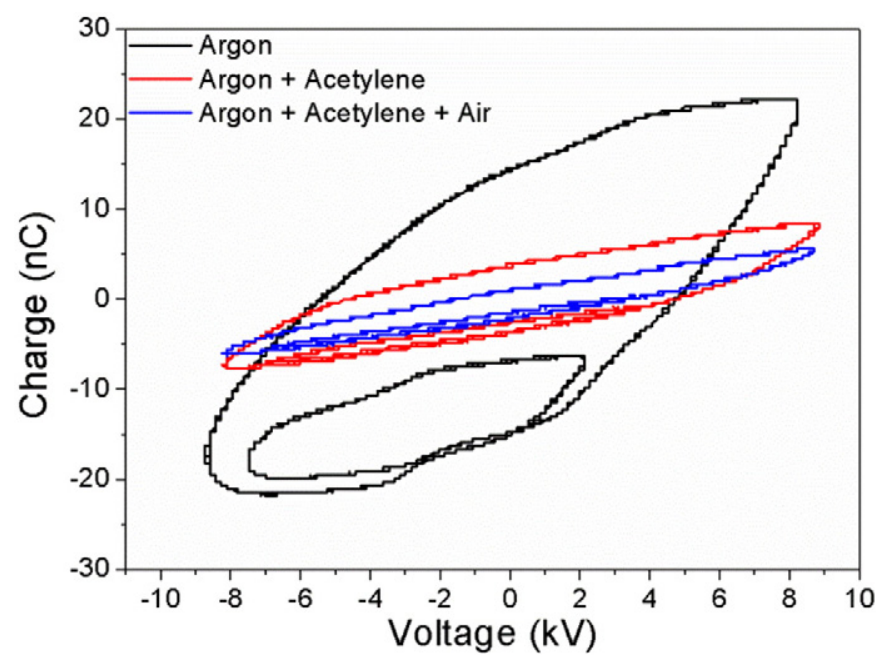

Fig. 4. Lissajous figures on the substrate electrode for different gas mixture.

the gases were mixed the proprieties of the system (the inclination of Q$\mathrm{V}$ plot) changed significantly.

The optical characterization of the extracted plasma plume showed the effect of acetylene and air admixture. As expected (taking into account the decrease of power), adding air and acetylene led to a significant decrease of the discharge light intensity and an increase in the ratio of $\mathrm{N}_{2}$ to $\mathrm{Ar}$ lines intensity. The spectra also contained weak lines of $\mathrm{C}-\mathrm{H}$ emission (around $430 \mathrm{~nm}$ ). The temperatures of plasma were estimated using SpecAir software for the nitrogen molecular bands in the region from $370 \mathrm{~nm}$ to $410 \mathrm{~nm}$. The estimated rotational temperature $T_{r}$ was $800 \pm 200 \mathrm{~K}$ (it is an rough approximation of gas temperature) and vibrational temperature $T_{v}$ was $3000 \pm 200 \mathrm{~K}$ (characterize electronic and molecular energy exchanges). Though the obtained plasma is not room-temperature, it is highly non-thermal as $T_{v} \ll T_{r}$. It is important to note that the simulated temperatures were about the same (within experimental error) for plasmas operated in $\mathrm{Ar}$ and in mixture $\mathrm{Ar} /$ air/acetylene. Fig. 5 shows the recorded spectrum for APPJ operated at deposition conditions $(0.45 \mathrm{~L} / \mathrm{min}$ of $\mathrm{Ar}, 0.045 \mathrm{~L} / \mathrm{min}$ of acetylene, $0.045 \mathrm{~L} / \mathrm{min}$ of air), containing lines of argon, $\mathrm{C}-\mathrm{H}$ and $\mathrm{N}_{2}$. Fig. 6 shows a simulation spectrum of $\mathrm{N} 2$ molecular bands used for estimation of plasma temperatures.

As plasma jet system usually produce non-uniform deposition, a study of film uniformity is an important issue. Fig. 7 shows thickness

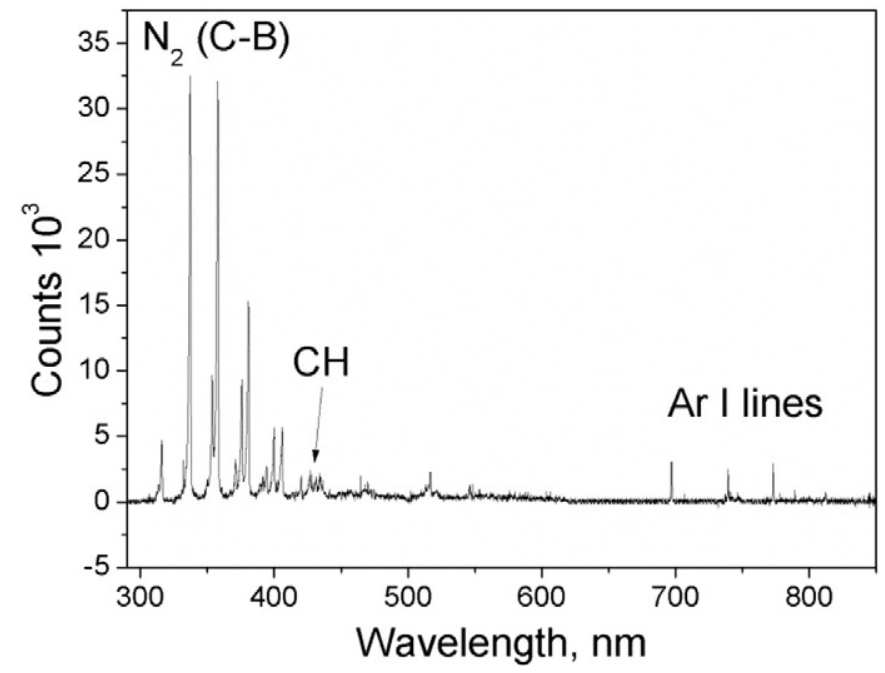

Fig. 5. The OES spectrum of APPJ showing a presence of weak $\mathrm{CH}$ bands. Plasma jet was operated in $\operatorname{Ar}(0.45 \mathrm{~L} / \mathrm{min})$, air $(0.045 \mathrm{~L} / \mathrm{min})$ and acetylene $(0.045 \mathrm{~L} / \mathrm{min})$ mixture.

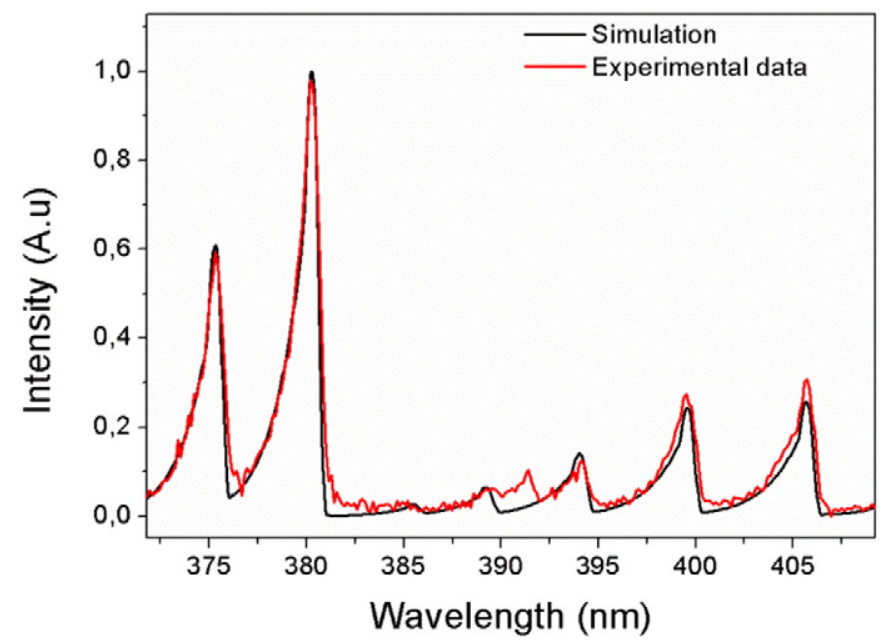

Fig. 6. The temperature of plasma was estimated using the SPECAIR program, $T_{r}=800 \pm$ $200 \mathrm{~K}$ and $T_{v}=3000 \pm 200 \mathrm{~K}$.

distributions of plasma polymerized film obtained at different deposition times for stationary jet. The deposition rate in the central part, were the film is more uniform, is about $1 \mu \mathrm{m} / \mathrm{min}$ for two minutes of deposition. However, it is important to note that the deposition rate slowly decreases with the deposition time. For example, $0.7 \mu \mathrm{m}$ film thickness was deposited during the third minute and $0.6 \mu \mathrm{m}$ during the fourth minute. Such behavior of deposition rate could be explained by simultaneous etching process. The full width half maximum (FWHM) obtained from the thickness profile increased with deposition time from $10.8 \mathrm{~mm}$ (for 2 min deposition) to $12.8 \mathrm{~mm}$ (for 4 min deposition time).

To improve the uniformity of deposited films a moveable platform was placed under the glass table. It can displace the whole table together with the sample with velocity of $3.5 \mathrm{~mm} / \mathrm{s}$ in one direction. The system was set to make a periodic displacement forth and back in Y direction with $2 \mathrm{~cm}$ amplitude, giving a total deposition length of $4 \mathrm{~cm}$. The total deposition time was increased (as a deposition at one spot was shorter compared with the one of static jet) up to $10 \mathrm{~min}$. The measurement of film thickness was performed in two perpendicular cuts done in the central part of the film, as it is shown in the Fig. 8(a) with dashed lines. Fig. 8(b) and (c) demonstrate thickness profiles of the film deposited with movement for deposition time of $8 \mathrm{~min}$. The area with constant film thickness (for the given deposition time and plasma jet operation conditions it was $2 \mu \mathrm{m}$ ) was estimated to be $44 \mathrm{~mm}$ long and $8 \mathrm{~mm}$ wide. Considering the internal tube diameter

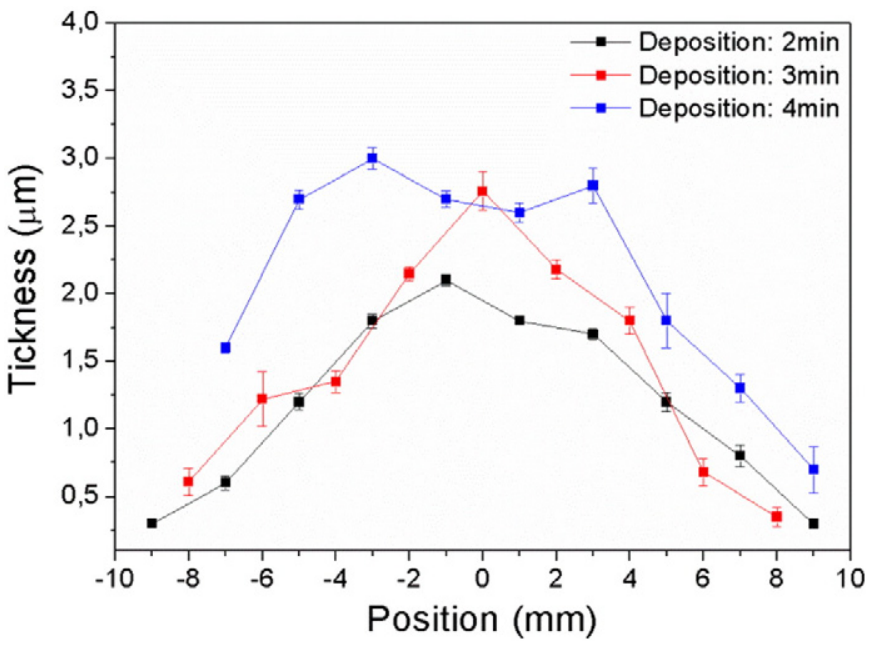

Fig. 7. Thickness profiles of the polymer films for $2 \mathrm{~min}, 3$ min and 4 min deposition time 

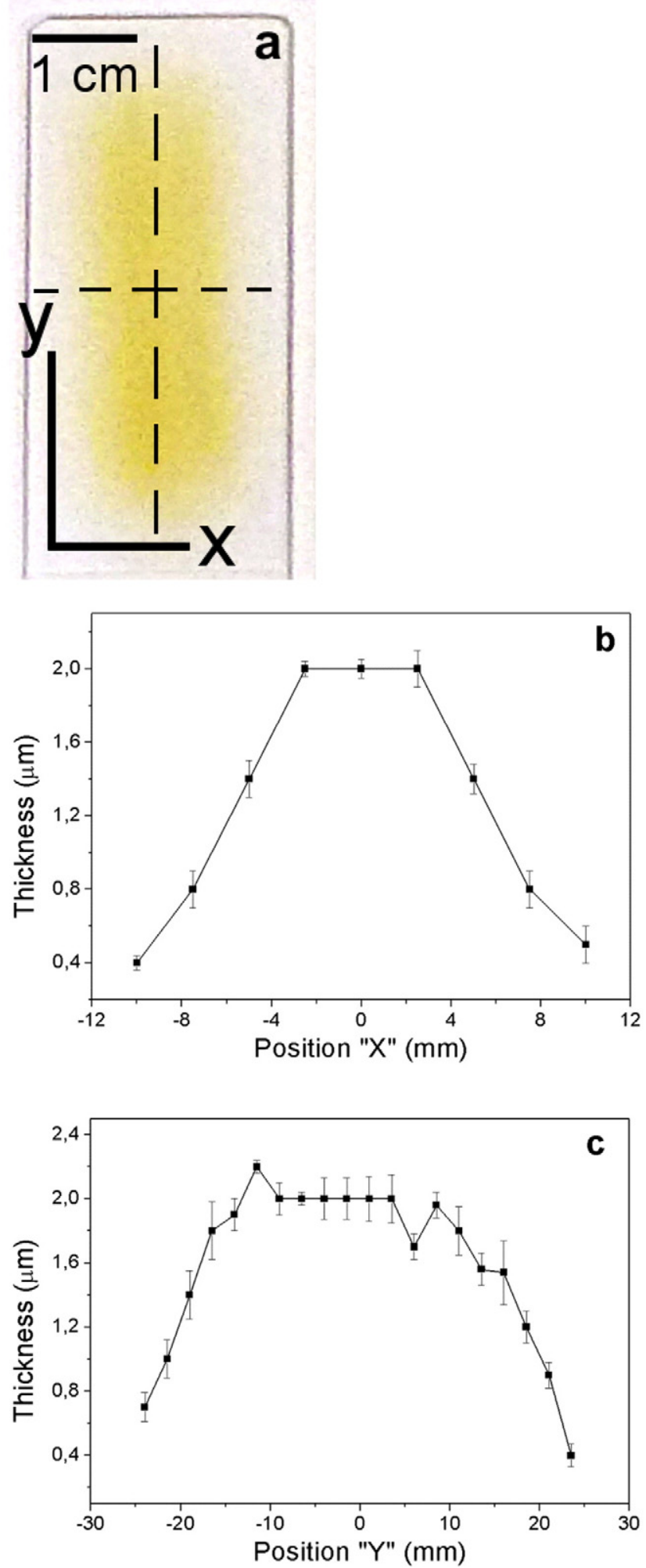

Fig. 8. a) Photo of the deposited film; b) film thickness profile measured in X direction; c) film thickness profile measured in Y direction.

of the APPJ ( $3.3 \mathrm{~mm}$ ) and the amplitude of movement $(4 \mathrm{~cm})$, it is possible to expect an easy scaling of such system simply by controlling the sample table movement.
Fig. 9 shows the thickness dependence on deposition time measured in the plato region. Unlike the case of static depositions, the deposition rate was found to be linear function of the time. Using a standard linear fit, the deposition rate of APPJ system was found to be about $330 \mathrm{~nm} /$ min.

Chemical composition of films was analyzed via infrared spectroscopy to observe the characteristic vibrations (Fig. 10). The IR spectrum of a glass slide that was used as substrates exhibit three peaks at $1020 \mathrm{~cm}^{-1}$, $900 \mathrm{~cm}^{-1}$ and $760 \mathrm{~cm}^{-1}$, which correspond to $\mathrm{Si}-\mathrm{O}$ and $\mathrm{Si}-\mathrm{O}-\mathrm{Si}$ vibrations. Several additional peaks were measured after the plasma deposition. Several $\mathrm{CH}_{2} / \mathrm{CH}_{3}$ vibration peaks were detected $\left(\mathrm{CH}_{3}\right.$ assym. str. at $2980 \mathrm{~cm}^{-1}, \mathrm{CH}_{2}$ assym. str. at $2940 \mathrm{~cm}^{-1}, \mathrm{CH}_{3}$ sym. str. at $2880 \mathrm{~cm}^{-1}, \mathrm{CH}_{3}$ assym. bend. at $1420 \mathrm{~cm}^{-1}$ and $\mathrm{CH}_{3}$ sym. bend at $1375 \mathrm{~cm}^{-1}$ and $1275 \mathrm{~cm}^{-1}, \mathrm{CH}_{2}$ sym. bend at $1350 \mathrm{~cm}^{-1}$ and $\mathrm{CH}_{2} /$ $\mathrm{CH}_{3}$ rock. at $870 \mathrm{~cm}^{-1}, 750 \mathrm{~cm}^{-1}$ and $700 \mathrm{~cm}^{-1}$ ) [29].

The peaks at $3390 \mathrm{~cm}^{-1}, 3220 \mathrm{~cm}^{-1}$ (H-bonded $\left.\mathrm{OH}\right), 1710 \mathrm{~cm}^{-1}$ (str. $\mathrm{C}=0$ ), $1600 \mathrm{~cm}^{-1}$ (sym. str. $\mathrm{C}=\mathrm{C}$ or amide group), $185 \mathrm{~cm}^{-1}$ (str. C-O) were also detected [30]. During long-term storage plasma polymerized films tend to change their chemical structure. For example, 2 month old films stored in air had a slightly different structure of vibration components. We observed changes in the ratio between $\mathrm{H}$-bonded $\mathrm{OH}$ bands, shift of the peak from $1600 \mathrm{~cm}^{-1}$ to $1630 \mathrm{~cm}^{-1}$ (can be

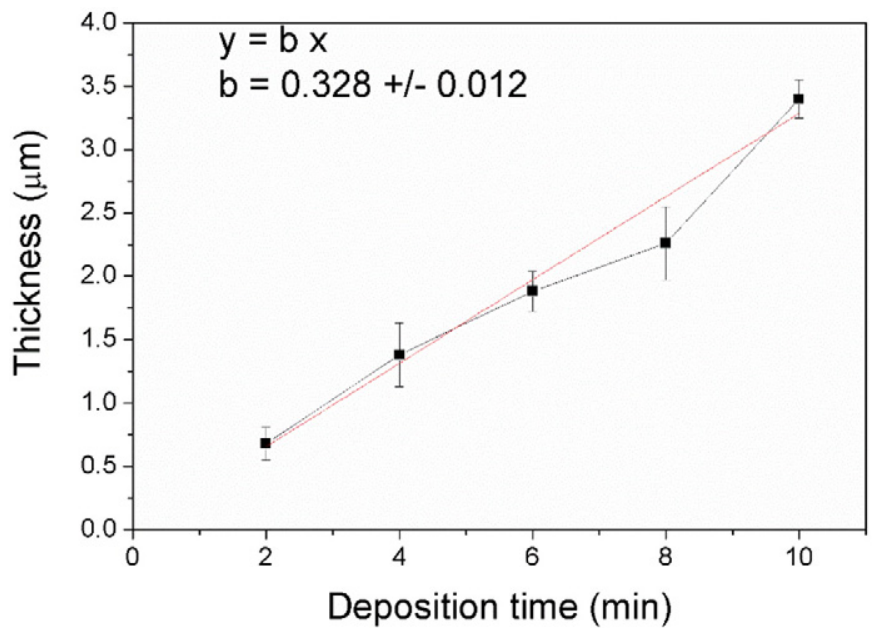

Fig. 9. Thickness of the deposited film depending on deposition time.

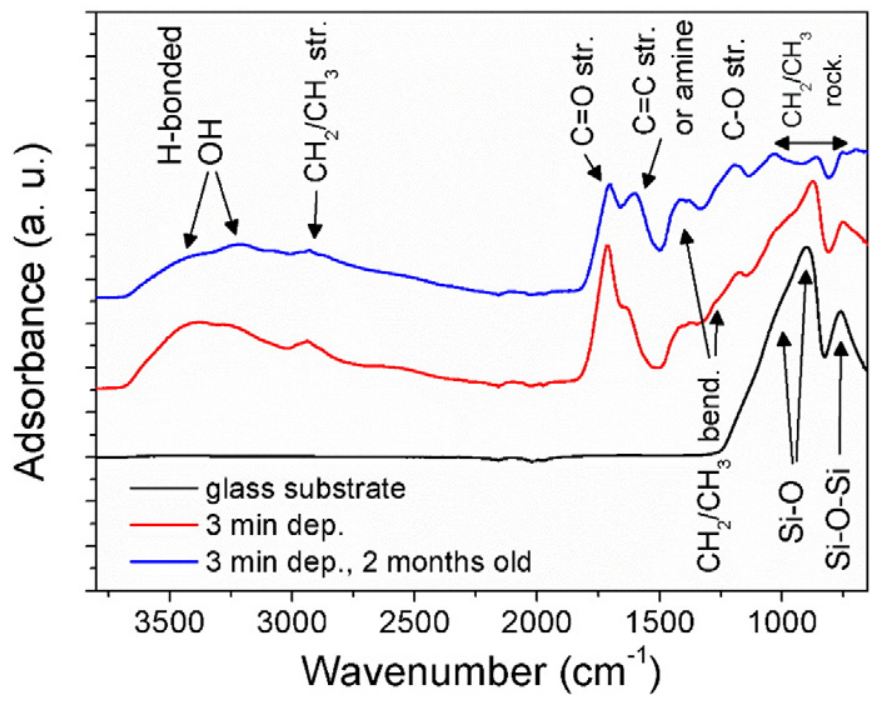

Fig. 10. FTIR spectra of (a) reference glass substrate, (b) plasma polymer after $3 \mathrm{~min}$ deposition and (c) 2 month aged plasma polymer after 3 min deposition. 
either attributed to change of $\mathrm{C}=\mathrm{C}$ bond or changed in amide group, this issue will be studied in detail in future), decrease of intensity of $\mathrm{CH}_{2} / \mathrm{CH}_{3}$ str. peaks at $2800-3000 \mathrm{~cm}^{-1}$ and small changes in weak $\mathrm{CH}_{2} / \mathrm{CH}_{3}$ peaks. For example, a peak position of $\mathrm{OH}$ band can be influenced by a position where $\mathrm{OH}$ radical is positioned [31], thus allowing us to conclude that there are chemical transformation in the deposited film. The post-plasma reactions in the plasma polymers (probably additional surface oxidation and hydration) will be a topic of future studies.

\section{Conclusions}

Polymer film depositions were performed using atmospheric plasma jet operated in mixture of argon, air and acetylene. To produce films without low-adherent powder requires certain conditions for gas flow and geometrical constrains. Admixture of air is necessary, Ar gas flow should be in the range of $0.4-0.6 \mathrm{~L} / \mathrm{min}$, acetylene and air flows should be about one order of magnitude smaller. The nozzle-to-sample distance should be no more than $5 \mathrm{~mm}$, the lower limit is defined by sparking between the HV electrode and the nozzle ground electrode. Adding acetylene and air led to a significant decrease of the total power (sum of the power calculated by Lissajous figures of both grounded electrodes) of APP from almost $11 \mathrm{~W}$ in Ar to $2.7 \mathrm{~W}$ under deposition conditions. The optical emission spectroscopy showed that plasma is highly non-thermal (with rotational temperature of about $800 \mathrm{~K}$ and vibrational temperature of about $3000 \mathrm{~K}$ ). The deposited film contained $\mathrm{OH}$ radicals and variety of carbon bonds: different bonds between carbon and hydrogen and few bonds between carbon and oxygen. The ratio between those bonds changed for aged films and it will be a topic of further studies.

By using a simple linear movement system, it is possible to get a uniform deposition over a large area, opening a possibility for scaling of the system. In the current setup, a deposition rate of about $330 \mathrm{~nm} / \mathrm{min}$ was achieved.

\section{Acknowledgements}

This research was financed by Fundação de Amparo à Pesquisa do Estado de São Paulo (FAPESP, 2013/06732-3) and Conselho nacional de desenvolvimento científico e tecnológico (CNPq, 470995/2013-0).

\section{References}

[1] F. Fanelli, F. Fracassi, Aerosol-assisted atmospheric pressure cold plasma deposition of organic-inorganic nanocomposite coating, Plasma Chem. Plasma Process. 34 (2014) 473-487.

[2] L. Bárdos, H. Baránková, Cold atmospheric plasma: sources, processes and applications, Thin Solid Films 518 (2010) 6705-6713.

[3] V. Nehra, A. Kumar, H.K. Dwivedi, Atmospheric non-thermal plasma sources, Int. J. Eng. 2 (2008) 53-67.

[4] X. Lu, M. Laroussi, V. Puech, On atmospheric-pressure non-equilibrium plasma jets and plasma bullets, Plasma Sources Sci. Technol. 12 (2012) 034005.

[5] F. Kraus, S. Cruz, J. Müller, Plasmapolymerized silicon organic thin film from HMDSN for capacitive humidity sensors, Sensors Actuators B Chem. 88 (2003) 300-311.

[6] D. Merche, N. Vandencasteele, F. Reniers, Atmospheric plasma for thin film deposition: a critical review, Thin Solid Films 520 (2012) 4219-4236.

[7] F. Fanelli, A.M. Mastrangelo, F. Fracassi, Aerosol-assisted atmospheric cold plasma deposition and characterization of superhydrophobic organic-inorganic nanocomposite thin film, Langmuir 30 (2014) 857-865.
[8] X. Liu, Q. Feng, A. Bachhuka, K. Vasilev, Surface modification by allylamine plasma polymerization promotes osteogenic differentiation of human adipose-derived stem cells, ACS Appl. Mater. Interfaces 6 (2014) 9733-9741.

[9] C. Sanchez, B. Julián, P. Belleville, M. Popall, Applications of hybrid organic-inorganic nanocomposites, J. Mater. Chem. 15 (2005) 3559-3592.

[10] J. Benedikt, V. Raballand, A. Yanguas-Gil, K. Focke, A. Von Keudell, Thin film deposition by means of atmospheric pressure microplasma jet, Plasma Phys. Controlled Fusion 49 (2007) B419-B427.

[11] T. Belmonte, G. Henrion, T. Gries, Nonequilibrium atmospheric plasma deposition, J. Therm. Spray Technol. 20 (4) (2011) 744-759.

[12] L.J. Ward, W.C.E. Schofield, J.P.S. Badyal, Atmospheric pressure glow discharge deposition of polysiloxane and $\mathrm{SiO}_{\mathrm{x}}$ films, Langmuir 19 (2003) 2110-2114

[13] J. Albaugh, C. O'Sullivan, L. O'Neill, Controlling deposition rates in an atmospheric pressure plasma system, Surf. Coat. Technol. 203 (2008) 844-847.

[14] L. Martinu, D. Poitras, Plasma deposition of optical films and coating: a review, J. Vac. Sci. Technol. A 18 (2000) 2646.

[15] E. Kedronova, L. Zajickova, D. Hegemann, M. Klima, M. Michlicek, A. Manakhov, Plasma enhanced CVD of organosilicon thin films on electrospun polymer nanofibers, Plasma Process. Polym. 12 (2015) 1231-1243.

[16] R.-S. Juang, K.-S. Chen, T.-C. Wei, C.-H. Liu, C.-Y. Tsai, H.-Y. Jheng, C. Huang, Surface characterization of argon/methane mixture atmospheric-pressure plasma-treated filtration poly(vinylidene fluoride) membrane and its flux enhancement, IEEE Trans. Plasma Sci. 42 (2014) 12.

[17] K. Rügner, R. Reuter, D. Ellerwer, T. de los Arcos, A. von Keudell, J. Benedikt, Insight into the reaction scheme of $\mathrm{SiO}_{2}$ film deposition at atmospheric pressure, Plasma Process. Polym. 10 (2013) 1061-1073.

[18] F. Fanelli, S. Lovascio, R. d'Angostino, F. Fracassi, Insights into the atmospheric pressure plasma-enhanced chemical vapor deposition of thin films from methyldisiloxane presursors, Plasma Process. Polym. 9 (2012) 1132-1143.

[19] M.C.M. van de Sanden, M.F.A.M. van Hest, A. de Graaf, A.H.M. Smets, K.G.Y Letourneur, M.G.H. Boogaarts, D.C. Schram, Plasma chemistry of an expanding Ar/ $\mathrm{C}_{2} \mathrm{H}_{2}$ plasma used for fast deposition of a-C:H, Diam. Relat. Mater. 8 (1999) 677-681.

[20] G. Le Dû, N. Celini, F. Bergaya, F. Poncin-Epaillard, RF plasma-polymerization of acetylene: correlation between plasma diagnostics and deposit characteristic, Surf. Coat Technol. 201 (2007) 5815-5821.

[21] S. Guimond, B. Hanselmann, M. Hossain, V. Salimova, D. Hegemann, Deposition of plasma polymer films from acetylene and water vapor, plasma process, Polymer 12 (2015) 328-335.

[22] Y. Yin, N.J. Nosworthy, H. Youssef, B. Gong, M. Bilek, D.R. McKenzie, Acetylene plasma coated surfaces for covalent immobilization of proteins, Thin Solid Films 517 (2009) 5343-5346.

[23] P.W.P. Moreira Jr., A.L.R. Rangel, L.S. Conejo, N.L. Batista, R.C. Deus, T.M.C. Nishime, F.V.P. Kodaira, K.A. Campos, M.B. Siqueira, K.G. Kostov, R.P. Mota, Acetylene plasma polymer treated by atmospheric dielectric barrier discharge, Vacuum 107 (2014) 195-198.

[24] E.C. Wemlinger, P.D. Pedrov, Acetylene deposition using atmospheric pressure weakly ionized plasma, IEEE Trans. Plasma Sci. 42 (2014) 6.

[25] G. Capote, G.C. Mastrapa, V.J. Trava-Airoldi, Influence of acetylene precursor diluted with argon on the microstructure and the mechanical and tribological properties of $\mathrm{a}-\mathrm{C}: \mathrm{H}$ films deposited via the modified pulsed-DC PECVD method, Surf. Coat. Technol. 284 (2015) 145-152.

[26] A. Ricci Castro, K. Kostov, V. Prysiazhnyi, Influence of nozzle shape on the performance of low-power Ar plasma jet, IEEE Trans. Plasma Sci. 43 (2015) 9.

[27] A. Manakhov, M. Michlicek, D. Necas, J. Polcak, E. Makneva, M. Elias, L. Zajickova, Carboxyl-rich coatings deposited by atmospheric plasma co-polymerization of maleic anhydride and acetylene, Surf. Coat. Tech. 295 (2016) 37-45.

[28] M. Leduc, S. Coulombe, R.L. Leask, Atmospheric pressure plasma jet deposition of patterned polymer films for cell culture applications, IEEE. Trans. Plasma Sci. 37 (2009) 6.

[29] D.R. McKenzie, R.C. McPhedran, N. Savvides, Analysis of films prepared by plasma polymerization of acetylene in a D.C. magnetron, Thin Solid Films 108 (1983) 247-256.

[30] S.F. Durrant, N. Margal, S.G. Castro, R.C.G. Vinhas, M.A. Bica de Moraes, J.H. Nicola, Mechanisms of polymer film deposition from r.f. discharges of acetylene, nitrogen and helium mixtures, Thin Solid Films 259 (1995) 139-145.

[31] S.D. Jacobsen, S. Demouchy, D.J. Frost, T.B. Ballaran, J. Kung, A systematic study of OH in hydrous wadsleyite from polarized FTIR spectroscopy and single-crystal X-ray diffraction: oxygen sites for hydrogen storage in Earth's interior, Am. Mineral. 90 (2015) 61-70. 